\title{
Release of Granulocyte Proteinases during Hemodialysis
}

\author{
Walter H. Hörl ${ }^{\text {a }}$, Marianne Jochum ${ }^{\text {b }}$, August Heidland ${ }^{\mathrm{a}}$, Hans Fritz ${ }^{\mathrm{b}}$

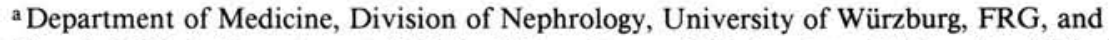 \\ bSurgical Clinic, Department of Clinical Chemistry and Biochemistry, University of Munich, FRG
}

Key Words. Granulocytes $\cdot$ Elastase $\cdot \alpha_{1}$-Proteinase inhibitor $\cdot$ Hemodialysis

\begin{abstract}
Neutral proteinases of neutrophilic polymorphonuclear leukocytes were followed up cytochemically in blood smears of 12 patients submitted to regular hemodialysis treatment (RDT). Halo formation (ring-shaped area around each neutrophil due to protein degradation) was reduced in all patients with end-stage renal disease under RDT. Concomitant to the development of leukopenia, a maximal increase of the plasma levels of the granulocytic elastase in complex with $\alpha_{1}$-proteinase inhibitor was observed $3 \mathrm{~h}$ after starting hemodialysis $(+409 \% ; \mathrm{p}<0.001)$. On the other hand, the proteolytic activity of the plasma samples against azocasein as substrate, being significantly higher $(+244 \% ; p<0.001)$ in RDT patients compared with healthy controls, decreased permanently during therapy $(-71 \%$; $\mathrm{p}<0.001 ; 3 \mathrm{~h}$ after initiation of the treatment). The mechanisms of release as well as of elimination of proteolytic activity due to RDT are discussed.
\end{abstract}

\section{Introduction}

Hemodialysis therapy is associated with a considerable loss of amino acids and glucose [1,2]. On the other hand, hepatic gluconeogenesis is enhanced during renal insufficiency [3-5]. Two possible causes of the reported increase in intradialytic protein catabolism [6] would be gluconeogenesis to replace glucose loss (during glucosefree dialysis) and protein breakdown to replace amino acid loss [7]. Glucose was found to be ineffective in reducing dialysis-induced catabolism. The average intradialytic urea generation was increased by $28 \%$ with glucose-free dialysis compared with 24 and $25 \%$, respectively, in the presence of glucose in the dialysate at a level of 11 or $26 \mathrm{mmol} / 1$ [7]. Furthermore, the replacement of the loss of amino acids during dialysis by continuous amino acid infusion did not lower intradialytic protein catabolism, but appeared to increase it [6].

Several studies have shown that proteinases participate in the protein catabolism of patients with hypercatabolic acute renal failure [8-11]. Therefore, we evaluated the possibility of enhanced protein breakdown by proteolytic enzymes liberated or activated during hemodialysis therapy. The rational for this is given by the high concentration of proteinases in neutrophil granulocytes and the well-known decrease of white blood cells followed by increased enzyme liberation after initiation of hemodialysis therapy - for review, see Heidland et al. [12]. The aim of our present study was twofold: (1) the cytochemical evaluation of neutral proteinases of neutrophilic polymorphonuclear (PMN) leukocytes of patients subjected to regular hemodialysis treatment (RDT), and (2) the detection of an increased liberation of the granulocytic proteinase elastase by measurement of the elastase- $\alpha_{1}$ proteinase inhibitor $\left(\mathrm{E}-\alpha_{1} \mathrm{PI}\right)$ complex in plasma samples of RDT patients. The plasma level of this complex was shown to be a suitable indicator of elastase liberation from activated or desintegrated granulocytes.

\section{Material and Methods}

We report here the results obtained in 12 chronically uremic patients ( 9 men), aged $47.3 \pm 4.0$ years (mean \pm SEM, range $22-66$ ), undergoing RDT for $41.3 \pm 11.6$ months (range 4-124). Hemodialysis was performed three times per week for $5 \mathrm{~h}$ with Gambro Lundia Optima and a glucose-free bath containing acetate. 4 patients suffered from diabetic glomerulosclerosis, 2 from polycystic kidney degeneration and 6 from chronic glomerulonephritis. Blood cells were counted by an electronic counter (Coulter-Counter-Model B). Further blood constituents were determined as follows: creatinine $11.5 \pm 0.8 \mathrm{mg} / \mathrm{dl}$ (range 7.2-16.9); urea nitrogen $76.9 \pm 4.7 \mathrm{mg} / \mathrm{dl}$ (range 54-105); hemoglobin $9.2 \pm 0.5 \mathrm{~g} / \mathrm{dl}$ (range 7.4-13.2), and 


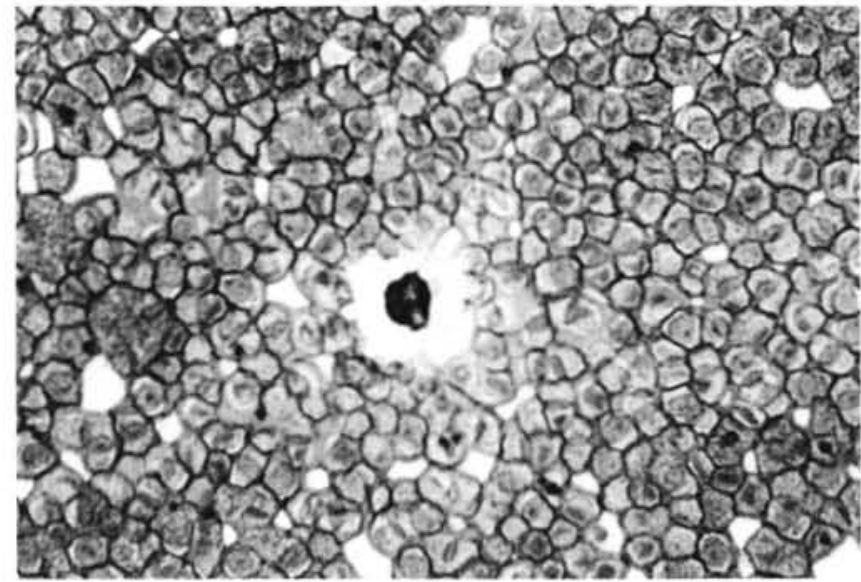

Fig. 1. Blood smear from a healthy subject. Fixation was performed using formaline sublimate. The smear was incubated with $0.25 \mathrm{M} \mathrm{NaCl}$ borate buffer ( $\mathrm{pH} 8.5$ ) for $120 \mathrm{~min}$ at $37^{\circ} \mathrm{C}$ and stained with colloidal iron.

hematocrit $30.3 \pm 1.7 \%$ (range $23.7-42.5$ ). Plasma samples were obtained by withdrawing $4.5 \mathrm{ml}$ of venous blood into plastic syringes containing $0.5 \mathrm{ml}$ of sodium citrate $(2.2 \mathrm{~g} / 100 \mathrm{ml}$ distilled water). Plasma was separated from blood within $30 \mathrm{~min}$ after sample collection to prevent leakage of leukocyte constituents. The plasma specimens were stored at $-70^{\circ} \mathrm{C}$ until assayed.

The inhibitory activity of antithrombin III (AT III) against thrombin was determined using the thrombin-specific chromogenic substrate S-2238 (Deutsche Kabi, Munich, FRG). The inhibitory activity of the $\alpha_{1}$-proteinase inhibitor ( $\alpha_{1} \mathrm{PI}=\alpha_{1}$-antitrypsin) was measured with a commercial test system (Boehringer, Mannheim, FRG). Plasma concentrations of $\alpha_{2}$-macroglobulin $\left(\alpha_{2} \mathrm{M}\right), \alpha_{1} \mathrm{PI}$, albumin as well as complement components $\mathrm{C}_{3}$ and $\mathrm{C}_{4}$ were evaluated by a radial immunodiffusion technique with standardized immunodiffusion plates (Behringwerke AG, Marburg, FRG).

Quantitative estimation of the plasma levels of the E- $\alpha_{1}$ PI complex was carried out with a highly sensitive enzyme-linked immunoassay [13]. Proteolytic activity of the plasma samples was measured using azocasein as substrate as previously described $[9,14]$. Proteinase activity of the neutrophilic PMN leukocytes was observed with the cytochemical test of Klessen [15].

Results were expressed as mean values \pm SEM. Statistical evalu. ation was performed by the Student's $t$ test.

\section{Results}

The cytochemical test of Klessen [15] was used to evaluate the activity of neutrophilic PMN leukocyte proteases. These enzymes are released from the PMN neutrophils of healthy subjects in blood smears following incubation with sodium chloride borate buffer. Proteolytic activity is revealed by a ring-shaped area around each neutrophil (fig. 1). This halo effect is due to erythro-

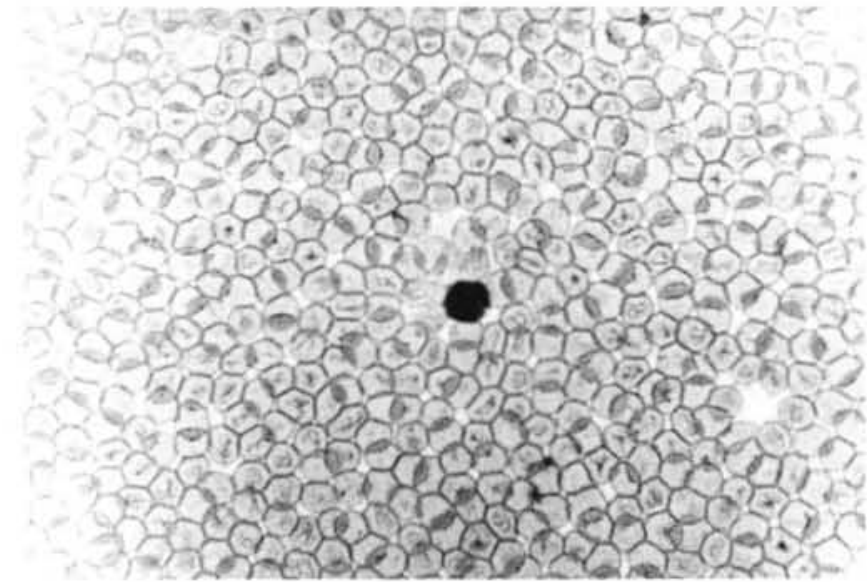

Fig. 2. Absence of halo formation in a blood smear of a RDT patient $30 \mathrm{~min}$ after initiation of hemodialysis therapy. For incubation conditions see legend to figure 1 .

cyte hemolysis and plasma protein degradation. Halo formation was reduced in the blood smears of all patients with end-stage renal disease undergoing RDT (fig. 2).

The effect of hemodialysis on leukocytes, plasma levels of the E- $\alpha_{1}$ PI complex as well as on $\alpha_{1}$ PI activity and concentration is shown in table I. There was a decrease of white blood cells $10 \mathrm{~min}(21.1 \%$; n.s. $)$ and $30 \mathrm{~min}$ $(41.1 \% ; p<0.001)$ after initiation of hemodialysis therapy. We observed maximum levels of the plasma E- $\alpha_{1} P I$ complex after $3 \mathrm{~h}(+409 \%$; $\mathrm{p}<0.001)$. However, plasma $\alpha_{1}$ PI activity and concentration were unchanged during hemodialysis therapy.

The plasma levels of $\alpha_{2} \mathrm{M}$ (before dialysis, $244 \pm 17$; after $3 \mathrm{~h}$ of dialysis therapy, $257 \pm 31 \mathrm{mg} / \mathrm{dl}$ ), AT III $(91.3 \pm 2.5$ vs. $95.2 \pm 4.3 \%)$, complement components $\mathrm{C}_{3}(154 \pm 6$ vs. $160 \pm 8 \mathrm{mg} / \mathrm{dl})$ or $\mathrm{C}_{4}(61.7 \pm 3.8 \mathrm{vs}$. $64.6 \pm 3.7 \mathrm{mg} / \mathrm{dl}$ ) remained also unchanged. Dialysis therapy was performed to maintain a constant body weight during the first $3 \mathrm{~h}$. Plasma albumin concentration $(3.77 \pm 1.12$ vs. $3.88 \pm 0.14 \mathrm{~g} / \mathrm{dl})$ or hematocrit $(30.3 \pm$ 1.7 vs. $31.3 \pm 2.0 \%$ ) were in the same range before and $3 \mathrm{~h}$ after starting hemodialysis therapy.

Using azocasein as a substrate, the proteolytic activity of the plasma samples was significantly higher $(+244 \%$; $p$ $<0.01$ ) before dialysis therapy compared with plasma samples of healthy controls $(0.052 \pm 0.004 \mathrm{U} / \mathrm{mg}$ protein). During dialysis therapy, however, there was a permanent decrease of this plasma proteinase activity $(0.127$ \pm 0.019 vs. $0.037 \pm 0.007 \mathrm{U} / \mathrm{mg} ;-71 \% ; \mathrm{p}<0.001$; table I). 
Table I. Effect of hemodialysis therapy on leukocyte counts, plasma E- $\alpha_{1}$ PI complex, proteinase activity as well as on activity and plasma concentration of $\alpha_{1} \mathrm{PI}$

\begin{tabular}{lcccccc}
\hline \multicolumn{7}{l}{ Time, $\min$} \\
\cline { 2 - 6 } & 0 & 10 & 30 & 60 & 120 & 180 \\
\hline Leukocytes, cells/mm $\mathrm{mm}^{3}$ & $7,133 \pm 582$ & $5,625 \pm 696$ & $4,200 \pm 251^{\mathrm{c}}$ & $6,658 \pm 441$ & $5,950 \pm 607$ & $7,192 \pm 824$ \\
E- $\alpha_{1} \mathrm{PI}, \mathrm{ng} / \mathrm{ml}$ & $188 \pm 20$ & $196 \pm 25$ & $326 \pm 56^{\mathrm{a}}$ & $373 \pm 32^{\mathrm{c}}$ & $602 \pm 84^{\mathrm{c}}$ & $769 \pm 128^{\mathrm{c}}$ \\
Proteinase activity, U/mg protein & $0.127 \pm 0.019$ & $0.103 \pm 0.014$ & $0.095 \pm 0.014$ & $0.087 \pm 0.013$ & $0.059 \pm 0.010^{\mathrm{b}}$ & $0.037 \pm 0.007^{\mathrm{c}}$ \\
$\alpha_{1} \mathrm{PI}, \mathrm{U} / \mathrm{ml}$ & $1.98 \pm 0.11$ & $1.89 \pm 0.11$ & $2.07 \pm 0.10$ & $2.06 \pm 0.09$ & $2.01 \pm 0.09$ & $2.08 \pm 0.11$ \\
$\alpha_{1} \mathrm{PI}, \mathrm{mg} / \mathrm{dl}$ & $254 \pm 14$ & $257 \pm 13$ & $268 \pm 13$ & $258 \pm 12$ & $260 \pm 11$ & $271 \pm 13$ \\
\hline
\end{tabular}

Mean values \pm SEM from 12 experiments before and during hemodialysis therapy.

${ }^{\mathrm{a}} \mathrm{p}<0.05 ;{ }^{\mathrm{b}} \mathrm{p}<0.01 ;{ }^{\mathrm{c}} \mathrm{p}<0.001$.

\section{Discussion}

It has been shown recently that glucose in the dialysate [7] as well as continuous amino acid infusion [6] are ineffective in preventing the pathological catabolic events observed during hemodialysis. The pathogenesis of hemodialysis-induced protein catabolism remains so far unclear. One pathogenetic factor could be the release of granulocyte proteinases after starting hemodialysis therapy. Craddock et al. [16] have demonstrated hemodialysisinduced leukopenia and pulmonary vascular leukostasis resulting from complement activation by dialyzer cellophane membranes.

Neutrophil granulocytes contain a broad variety of agents that are involved in the defence and digestion of invading microorganisms [17]. These include elastase $[17,18]$, cathepsin G, cathepsin B, cathepsin D and collagenase [19-24]. Lysosomal proteinases are not exclusively restricted to their intracellular compartment, the lysosomes. They may be released intra- as well as extracellularly during phagocytosis, exposure to antigen-antibody complexes, complement components and toxic substances such as endotoxins or during cell death $[25,26]$. Especially under pathological conditions massive release of proteases and other lysosomal factors may occur. They might cause tissue injury $[27,28]$ and consumption of plasma proteins by unspecific proteolytic degradation as soon as the levels of the controlling proteinase inhibitors in plasma and tissues are insufficient [29].

Granulocyte elastase is the most potent candidate for unspecific degradation because of its broad substrate specificity and the large amount present in the PMN granulocytes - for review, see Heidland et al. [12]. It degrades various plasma proteins such as transferrin [ $\mathrm{JO}$ - chum and Lander, unpublished data], immunoglobulins $[30,31]$ and fibronectin [32]. In vitro elastase rapidly inactivates fibrinogen $[33,34]$ and several other clotting factors [35, 36]. It also causes a limited degradation of the third and fifth factor of human complement [37, 38].

Granulocyte elastase could be released during hemodialysis due to the contact of blood cells with the blood lines and the dialyzer membrane (cuprophane). Such contact may result in a so-called 'frustrated phagocytosis' known to be associated with an extracellular release of lysosomal proteinases. The reduced proteolytic activity of PMN leukocytes in blood smears obtained $30 \mathrm{~min}$ after onset of hemodialysis and the concomitant increase of $E-\alpha_{1}$ PI plasma levels may be regarded as possible indicators of this 'escape' reaction. On the other hand, proteinase release due to cell death must be also taken into account. Since, however, leukopenia does not strictly parallel the increase of the E- $\alpha_{1}$ PI levels during hemodialysis, pulmonary vascular leukostasis resulting from complement activation by dialyzer cellophane membranes may be an additional source of local lysosomal enzyme release [16]. This event could indeed be responsible for the delayed release of elastase into the circulation. Although plasma activity and concentration of $\alpha_{1} \mathrm{PI}$, the dominating elastase inhibitor [39], were unchanged during hemodialysis therapy (table I), the liberation of granulocytic elastase together with other lysosomal enzymes, primarily within the lung, might lead to a repeated local proteinase-proteinase inhibitor imbalance [40-42] thus favoring pulmonary disease in long-term RDT patients.

The deleterious release of granulocytic proteinases during hemodialysis is partly counteracted by the diminution of 'unspecific' proteolytic (azocasein-hydrolyzing) 
activity accumulated in plasma in the dialysis-free interval. The decrease of this unspecific proteolytic activity during hemodialysis might be caused by the removal of yet unidentified low molecular weight factors. Such factors could stimulate the activation of proenzymes (e.g. plasma prokallikrein) or the release of lysosomal proteinases into the plasma of untreated patients. They might also be responsible for the stimulation of phagocytosis and/or increased protein breakdown within the cells. Characterization of the azocasein-splitting activity using more specific substrates might be a helpful tool in evaluating the origin and nature of this proteolytic effect.

Summarizing our results, we could clearly demonstrate that hemodialysis therapy is still connected with considerable side effects probably due to the contact of white blood cells with the dialyzer cellophane membranes. Improvement of such membranes leading to reduced liberation of proteolytic cell constituents should, therefore, enhance the positive effects of hemodialysis therapy.

\section{Acknowledgement}

This work was supported by the Deutsche Forschungsgemeinschaft, Ho 781/3-2 and Sonderforschungsbereich 51, München.

We are very grateful to Dr. S. Neumann and Dr. H. Lang, Biochemical Research Department of E. Merck, Darmstadt, for providing us with the enzyme-linked immunoassay. The excellent technical assistance of Mrs. M. Röder and Mrs. U. Hof as well as the secretarial help of Miss M. Eiring is greatly appreciated.

\section{References}

1 Kopple, J.; Swendseid, M.; Shinaberger, J.; Umezawa, C.: The free and bound amino acids removed by hemodialysis. Trans. Am. Soc. artif. internal Organs 19: 309-313 (1973).

2 Wathen, R.; Keshaviah, P.; Hommeyer, P.; Cadwell, K.; Comty, C.: Role of dialysate glucose in preventing gluconeogenesis during hemodialysis. Trans. Am. Soc. artif. internal Organs 23: 393398 (1977).

3 Hörl, W.; Stepinski, J.; Heidland, A.: Carbohydrate metabolism and uraemia - mechanisms for glycogenolysis and gluconeogenesis. Klin. Wschr. 58: 1051-1064 (1980).

4 Stepinski, J.; Hörl, W.; Heidland, A.: The gluconeogenetic ability of hepatocytes in various types of acute uraemia. Nephron 31 : 75-81 (1982).

5 Riegel, W.; Stepinski, J.; Hörl, W.; Heidland, A.: Effect of hormones on hepatocytes gluconeogenesis in different models of acute uraemia. Nephron 32: 67-72 (1982).

6 Gotch, F.; Borah, M.; Keen, M.; Sargent, J.: The solute kinetics of intermittent dialysis therapy (IDT). Proc. Annu. Contractors Conf. artif. Kidney Program, vol. 10, pp. 105-111 (NIAMDD, Washington 1977).
7 Farrell, P.; Hone, P.: Dialysis-induced catabolism. Am. J. clin. Nutr. 33: 1417-1422 (1980).

8 Hörl, W.; Heidland, A.: Enhanced proteolytic activity - cause of protein catabolism in acute renal failure. Am. J clin. Nutr. 33: 1423-1427 (1980).

9 Hörl, W.; Stepinski, J.; Gantert, C.; Hörl, M.; Heidland, A.: Evidence for the participation of proteases on protein catabolism during hypercatabolic renal failure. Klin. Wschr. 59: 751-759 (1981).

10 Hörl, W.; Gantert, C.; Auer, I.; Heidland, A.: In vitro inhibition of protein catabolism by alpha ${ }_{2}$-macroglobulin in plasma from a patient with posttraumatic acute renal failure. Am. J. Nephrol. 2: 33-37 (1982).

11 Hörl, W.; Stepinski, J.; Schäfer, R.; Heidland, A.: Role of proteases in hypercatabolic patients with renal failure. Kidney int. (in press).

12 Heidland, A.; Hörl, W.; Heller, N.; Heine, H.; Neumann, S.; Heidbreder, E.: Proteolytic enzymes and catabolism - enhanced release of granulocyte proteinases in uremic intoxication and during hemodialysis. Kidney int. (in press).

13 Neumann, S.; Hennrich, N.; Gunzer, G.; Lang, H.: Enzymelinked immunoassay for human granulocyte $\alpha_{1}$-proteinase inhibitor complex; in Goldberg, Werner, Progress in clinical enzymology (Masson, New York, in press, 1983).

14 Hörl, W.; Schäfer, R.; Heidland, A.: Role of urinary alpha ${ }_{1}$-antitrypsin in Padutin (kallikrein) inactivation. Eur. J. clin. Pharma. col., Berlin 22: 541-544 (1982).

15 Klessen, C.: On testing the activity of proteases from human polymorphonuclear neutrophils on blood smears. J. Biochem. Cytochem. 26: 759-760 (1978).

16 Craddock, P.; Fehr, J.; Dalmasso, A.; Brigham, K.; Jacob, H.: Hemodialysis leukopenia. Pulmonary vascular leukostasis resulting from complement activation by dialzyer cellophane membranes. J. clin. Invest. 59: 879-888 (1977).

17 Blondin, J.; Janoff, A.: The role of lysosomal elastase in the digestion of Escherichia coli proteins by human polymorphonuclear leukocytes. J. clin. Invest. 58: 971-979 (1976).

18 Janoff, A.; Scherer, J.: Mediators of inflammation in leukocyte lysosomes. IX. Elastolytic activity in granules of human polymorphonuclear leukocytes. J. exp. Med. 128: 1137-1155 (1968).

19 Rindler, R.; Schmalzl, F.; Braunsteiner, H.: Isolierung und Charakterisierung der chymotrypsinähnlichen Protease aus neutrophilen Granulozyten des Menschen. Schweiz. med. Wschr. 104: 132-133 (1974).

20 Baggiolini, M.; Bretz, U.; Dewald, B.: Subcellular localization of granulocyte enzymes; in Havemann, Janoff, Neutral proteases of human polymorphonuclear leukocytes, pp. 3-17 (Urban \& Schwarzenberg, Baltimore 1978).

21 Lazarus, G.; Daniels, J.; Brown, R.; Bladen, H.; Fullmer, H.: Degradation of collagen by a human collagenolytic system. J. clin. Invest. 47: 2622-2628 (1968).

22 Ohlsson, K.; Olsson, J.: The neutral proteases of human granulocytes. Isolation and partial characterization of two granulocyte collagenases. Eur. J. Biochem. 36: 473-481 (1973).

23 Bretz, U.; Baggiolini, M.: Biochemical and morphological characterization of azurophil and specific granules of human neutrophilic polymorphonuclear leukocytes. J. Cell Biol. 63: 251-269 (1974).

24 Murphy, G.; Reynolds, S.; Bretz, U.; Baggiolini, M.: Collagenase 
is a component of the specific granules of human neutrophil leukocytes. Biochem. J. 162: 195-197 (1977).

25 Janoff, A.; Blondin, J.; Sandhaus, R.; Mosser, A.; Malemud, C.: Human neutrophil elastase: in vitro effects on natural substrates suggest important physiological and pathological action; in Reich, Proteases and biological control, pp. 603-630 (Cold Spring Harbor Laboratory, Cold Spring Harbor 1975).

26 Smolen, J.; Weissmann, G.: The granulocyte: metabolic properties and mechanisms of lysosomal enzyme release; in Havemann, Janoff, Neutral proteases of human polymorphonuclear leukocytes, pp. 56-76 (Urban \& Schwarzenberg, Baltimore 1978).

27 Janoff, A.; Zeligs, J.: Vascular injury and lysis of basement membrane in vitro by neutral protease of human leukocytes. Science 161: 702-706 (1968).

28 Cochrane, C.; Janoff, A.: The Arthus reaction. A model of neutrophil and complement mediated injury; in Zweifach, Grant, McCluskey, The inflammatory process, pp. 121-131 (Academic Press, New York 1974).

29 Fritz, H.: Proteinase inhibitors in severe inflammatory processes (septic shock and experimental endotoxemia): biochemical, pathophysiological and therapeutic aspects. Ciba Fdn Symp. (New Series): Protein degradation in health and disease, vol. 75, pp. 351-379 (Excerpta Medica, Amsterdam 1980).

30 Solomon, A.; Schmidt, W.; Havemann, K.: Bence Jones proteins and light chains of immunoglobulins. XIII. Effect of elastase-like and chymotrypsin-like neutral proteases derived from human granulocytes on Bence Jones proteins. J. Immun. 117: 1010-1014 (1976).

31 Solomon, A.: Possible role of PMN proteases in immunoglobulin degradation and amyloid formation; in Havemann, Janoff, Neutral proteases of human polymorphonuclear leukocytes, pp. 423436 (Urban \& Schwarzenberg, Baltimore 1978).

32 McDonald, J.; Kelly, D.: Degradation of fibronectin by human leukocyte elastase. J. biol. Chem. 255: 8848-8856 (1980).

33 Ohlsson, K.; Olsson, J.: The neutral proteases of human granulocytes. Isolation and partial characterization of granulocyte elastases. Eur. J. Biochem. 42: 519-527 (1974).

34 Plow, E.: Leukocyte elastase release during blood coagulation. A potential mechanism for activation of alternative fibrinolytic pathway. J. clin. Invest. 69: 564-572 (1982).
35 Jochum, M.; Lander, S.; Heimburger, N.; Friț, H.: Effect of human granulocytic elastase on isolated human antithrombinIII. Hoppe-Seyler's Z. physiol. Chem. 362: 103-112 (1981).

36 Schmidt, W.; Egbring, R.; Havemann, K.: Effect of elastase-like and chymotrypsin-like neutral proteases from human granulocytes on isolated clotting factors. Thromb. Res. 6: 315-326 (1975).

37 Johnson, U.; Ohlsson, K.; Olsson, J.: Effects of granulocyte neutral proteases on complement components. Scand. J. Immunol 5: 421-426 (1976).

38 Taylor, J.; Crawford, J.; Hugli, T.: Limited degradation of the third component $(\mathrm{C} 3)$ of human complement by human leukocyte elastase (HLE), partial characterization of C3 fragments. Biochemistry 16: 3390-3396 (1977).

39 Travis, J.; Giles, P.; Porcelli, L.; Reilly, C.; Baugh, R.; Powers, J.: Human leukocyte elastase and cathepsin G.: structural and functional characteristics. Ciba Fdn Symp. (New Series): Protein degradation in health and disease, vol. 75, pp. 51-68 (Excerpta Medica, Amsterdam 1980).

40 Cohen, A.: The effects in vivo and in vitro of oxidative damage to purified alpha ${ }_{1}$-antitrypsin and to the enzyme inhibiting activity of plasma. Am. Rev. resp. Dis. 119: 953-960 (1979).

41 Matheson, N.; Wong, P.; Travis, J.: Enzymatic inactivation of human alpha ${ }_{1}$-proteinase inhibitor by neutrophil myeloperoxidase. Biochem. biophys. Res. Commun. 88: 402-409 (1979).

42 Gadek, J.; Fells, G.; Zimmerman, R.; Rennard, S.; Crystal, R.: Antielastases of the human alveolar structures. Implications for the protease-antiprotease theory of emphysema. J. clin. Invest. 68: 889-898 (1981).

Received: November 21, 1982

Accepted: December 26, 1982

Walter H. Hörl, MD, PhD, Medizinische Universitätsklinik, Josef-Schneider-Strasse 2, D-8700 Würzburg (FRG) 